\title{
TIME em Ação: Teoria e Investigação em Matemática Elementar
}

\author{
TIME in Action: Theory and Research in Elementary Mathematics
}

\author{
Vinícius Murilo Fratucci \\ Universidade Estadual de Maringá (UEM), Maringá, PR, Brasil \\ https://orcid.org/0000-0001-8486-505X, viniciusfratucci@outlook.com
}

Mariana Moran

Universidade Estadual de Maringá (UEM), Maringá, PR, Brasil https://orcid.org/0000-0001-8887-8560, mmbarroso@uem.br

Eduardo de Amorim Neves

Universidade Estadual de Maringá (UEM), Maringá, PR, Brasil https://orcid.org/0000-0002-6716-0450, eaneves@uem.br

Thiago Fanelli Ferraiol

Universidade Estadual de Maringá (UEM), Maringá, PR, Brasil https://orcid.org/0000-0001-6573-8311, tfferraiol@uem.br

\begin{tabular}{l}
\multicolumn{1}{c}{ Informações do Artigo } \\
\hline Como citar este artigo \\
FRATUCCl, Vinícius Murilo; MORAN, \\
Mariana; NEVES, Eduardo de Amorim; \\
FERRAIOL, Thiago Fanelli. TIME em Ação: \\
Teoria e Investigação em Matemática \\
Elementar. REMAT: Revista Eletrônica da \\
Matemática, Bento Gonçalves, RS, v. 6, n. 1, \\
p. 01-14, jan. 2020. DOI: \\
https://doi.org/10.35819/remat2020v6i1id3543
\end{tabular}

https://doi.org/10.35819/remat2020v6i1id3543

\section{Histórico do Artigo}

Submissão: 6 de agosto de 2019.

Aceite: 18 de novembro de 2019.

\author{
Palavras-chave \\ Investigação Matemática \\ Resolução de Problemas \\ Oficinas \\ Educação Matemática
}

\begin{abstract}
Resumo
O objetivo deste trabalho é descrever e analisar algumas atividades realizada no projeto de extensão chamado Teoria e Investigação em Matemática Elementar (TIME), que é executado por professores do Departamento de Matemática da Universidade Estadual de Maringá. Tal projeto é destinado a estudantes e professores da Educação Básica, e utiliza abordagens na forma de Resolução de Problemas, Oficinas e Investigação Matemática. Este vem ganhando destaque na região de Maringá pelas suas iniciativas e resultados em competições olímpicas de Matemática, levando-nos a querer entender como são seus encontros, suas abordagens metodológicas, sua organização e os resultados a respeito da participação e aprendizagem de seus frequentadores. Nesse sentido, realizamos uma pesquisa qualitativa, que segue o paradigma interpretativo na modalidade de observação participante. Seguindo esses caminhos, observamos o funcionamento de 3 oficinas que foram realizadas durante alguns dos encontros do TIME no ano de 2018. Os resultados desta pesquisa mostram que o TIME propicia um espaço de experimentação metodológica para os alunos e professores do curso de Matemática, além de contribuir para que seus participantes percebam como o conhecimento matemático é construído, realçando assim o pensamento crítico e criativo. Desta maneira, o projeto contrasta com o ensino tradicional, que de modo geral apresenta a Matemática como um conhecimento pronto e acabado, exposto de forma sequencial pautado em axiomas, definições, teoremas, demonstrações, exemplos e exercícios de fixação.
\end{abstract}

\section{Abstract}

The goal of this paper is to describe and analyse some activities carried out in the extension project called Theory and Research and Elementary Mathematics (TIME), which is run by teachers of the Department of Mathematics at the Universidade Estadual de Maringá. Aimed at students and teachers of Basic Education, it uses approaches in the form of Problem Solving, Workshops and

\footnotetext{
Keywords

Mathematical Investigation

Problems Solving

Workshops

Mathematics Education
} 
Mathematical Research methodology. This project has gained prominence in Maringá and region for its approaches and results in olympic competitions of Mathematics, leading us to want to understand how their meetings, their methodological approaches, their organization and the results regarding the participation and learning of their attendees. In this sense, we conducted a qualitative research, which follows the interpretative paradigm in the participant observation modality. Following these paths, we observed the operation of 3 workshops that were held during some of the TIME meetings in 2018. The results of this research show that the TIME provides a space of methodological experimentation for students and teachers of the Mathematics degree, besides contributing to its participants understand how mathematical knowledge is built, thus enhancing critical and creative thinking. Thus, the project contrasts with traditional teaching, which generally presents mathematics as a ready and finished knowledge, sequentially exposed based on axioms, definitions, theorems, demonstrations, examples and fixation exercises.

\section{Introdução}

Ao longo da última década, tem-se notado uma procura cada vez mais baixa pelos cursos de Matemática no Brasil. Tal fato se confirma por meio de uma pesquisa realizada por Gomes (2014) que revela a escassez de professores, sobretudo nas áreas de Matemática, Física e Química. No caso específico da Universidade Estadual de Maringá, a concorrência em número de candidatos por vaga foi maior que 5 no final da década de 1990 e menor que 2 em 2018. Isso se contrapõe a crescente necessidade de professores em todo o nosso país.

Além disso, a Matemática se encontra entre as disciplinas da Educação Básica que possui um dos mais altos índices de reprovação, conforme dados do INEP (2011). Não podemos atribuir tal situação a um único fator, no entanto, no Brasil o modo como a Matemática é ensinada ainda prioriza "pela formalização precoce de conceitos, pela excessiva preocupação com o treino de habilidades e mecanização de processos sem compreensão" (BRASIL, 1998, p. 19). Deste modo, D’Ambrósio (1991, p. 1) conclui: "há algo de errado com a matemática que estamos ensinando".

Seguindo esta mesma ideia, Pais (2002, p. 9) faz o seguinte questionamento: "O ensino de matemática pode se resumir à apresentação de uma sequência de axiomas, definições e teoremas?". Acredita-se que para obter êxito nos processos de ensino e de aprendizagem, o professor deve realizar juntamente com os alunos experiências que atraiam a atenção destes e que tornem as aulas mais produtivas, inclusive matematicamente. No entanto, os exercícios de aplicação, que conectam a Matemática com a realidade, também são enfrentados pelos alunos com dificuldade e resistência. Acreditamos que isso seja fruto de uma tendência mecanicista que cerca o aluno em toda sua vida pré-universitária e que constantemente o empurra a uma situação de conforto em aprender a efetuar os cálculos sem se importar com seus significados. É uma conduta que tem se adaptado bem em uma educação orientada para o vestibular, cujas provas vêm permitindo tal abordagem, mas é de extrema nocividade à formação do indivíduo. 
Nesta concepção, temos o seguinte pensamento:

A matemática é vista como uma disciplina que se encerra em si mesma, que já está pronta e que deve ser aprendida, desqualifica-a enquanto ciência e campo de conhecimento e pesquisa, outorgando apenas a alguns o poder de conhecê-la e estudá-la (LAMONATO; PASSOS, 2011, p. 54).

Considerando tais reflexões, apresentaremos o projeto de extensão Teoria e Investigação em Matemática Elementar (TIME) que é implementado na Universidade Estadual de Maringá (UEM), localizada ao norte do Paraná. Neste projeto, alunos e professores da Educação Básica conhecem e estudam a Matemática de modo diferente e criativo, explorando o potencial que a Matemática pode nos oferecer na forma de conhecimento, sem se restringir a aspectos mecanicistas.

Os primeiros três anos do projeto foram basicamente direcionados a alunos que tinham interesse em participar de competições de olimpíadas de Matemática, por essa razão era realizado aulas expositivas e resolução de problemas que eram propostos nas olimpíadas. No ano de 2013, no início do projeto, o nome era Treinamento Intensivo em Matemática Elementar, os encontros eram quinzenais. Já em 2014 e 2015, vinculado aos Pólos Olímpicos de Treinamento Intensivo (POTI), os encontros passaram a ser semanais e com conteúdo mais direcionados para olimpíadas de Matemática. A intenção das primeiras propostas didáticas se baseava na resolução de problemas de questões de olimpíadas de Matemática. Contudo, percebeu-se que a própria natureza dos problemas proporciona a todos um "pensar matemático" diferente dos tecnicismos dos exercícios de fixação ou da linearidade dos formalismos dos livros de Matemática. De modo geral, os problemas de olimpíadas de Matemática não tem uma fórmula pronta e fechada que, quando aplicada, fornece imediatamente a resposta do problema. Da mesma forma, não é possível apenas ler a solução de um problema específico a fim de reproduzi-la em situações análogas. Para resolver problemas de olimpíadas, necessita-se um envolvimento tanto cognitivo quanto afetivo com o próprio processo, criando perspectivas de superação de desafios. De fato, estes problemas exigem investigação, busca de padrões, conjecturas e testes de hipóteses.

Deste modo, tendo em vista que o projeto se restringia somente ao público que se interessava em competir em olimpíadas de Matemática, sentiu-se a necessidade de expandi-lo a todos aqueles que se interessassem em aprender mais da Matemática. E assim, em 2016 o nome do projeto TIME foi mudado de Treinamento Intensivo em Matemática Elementar para Teoria e Investigação em Matemática Elementar, e as atividades foram estruturadas em forma de oficinas que incrementaram naturalmente questões interdisciplinares fundamentadas em metodologias mais dinâmicas e colaborativas, colocando ativamente os alunos juntamente com seu grupo, e despertando a curiosidade necessária para um envolvimento destes com o conhecimento. A partir desse momento, foi possível verificar que tais metodologias proporcionaram aos seus participantes um olhar mais amplo da Matemática e, assim, o projeto de extensão TIME poderia alcançar a todos os alunos que tivessem interesse em conhecer outras facetas da Matemática, 
incluindo aqueles com certa dificuldade para que assim pudesse ser um programa que alcançasse um maior número de interessados. Por consequência, nos anos seguintes avançou-se com a metodologia de oficinas e, conforme foi aperfeiçoando, ampliou-se as oficinas para públicos distintos, desde alunos da Educação Básica a professores da Educação Básica e alunos de graduação. Consequentemente, o desenvolvimento metodológico das oficinas varia de acordo com o tema e o público contemplando as investigações dos alunos.

Nos dias atuais, o projeto de extensão TIME consiste na proposta de realização de Investigações Matemáticas e Resoluções de Problemas a partir de oficinas que são oferecidas e realizadas com alunos e professores do Ensino Fundamental e Médio, sob coordenação de docentes do Departamento de Matemática da UEM. O projeto conta também com o auxílio de discentes do curso de Matemática. As abordagens metodológicas que o TIME utiliza são Investigação Matemática e Resolução de Problemas, com o objetivo cognitivo de desenvolver as componentes da criatividade e construir o conhecimento matemático.

Nas aulas do TIME, os participantes se unem semanalmente aos sábados de manhã, integrando, assim, alunos de diferentes escolas, classes e faixas etárias, possibilitando uma "troca" de informações e conhecimento entre os participantes. Além disso, os alunos são instigados a investigar situações problema com intuito de eles observarem padrões e fazerem suas próprias conjecturas, sem que estes sejam disponibilizados pelos professores de modo pronto e acabado, ou seja, há um trabalho enfatizado nos aspectos relacionados à curiosidade científica, que promove a construção do conhecimento por meio de aspectos belos e desafiadores se contrapondo a métodos mecânicos de ensino e de aprendizagem.

Programas deste mesmo formato foram as portas de entrada para a Matemática de muitos matemáticos brasileiros renomados, como Nicolau Saldanha, Carlos Gustavo Tamm de Araújo e o premiado Artur Ávila e outros que, apesar de contar com publicações ou palestras internacionais em seus currículos, trabalham para a formação de muitos jovens. Os impactos vão além da formação de matemáticos, mas de todos os profissionais como os de Ciências Exatas e Engenharias, campos fundamentados na Matemática, e profissionais de outras áreas que vêm apresentando ultimamente conexões interdisciplinares com a Matemática.

Desta forma, com o interesse em investigar o modo como a aprendizagem da Matemática vem sendo trabalhada no contexto das oficinas do TIME, realizou-se esta pesquisa com o objetivo de apresentar algumas das atividades desenvolvidas nos encontros, demonstrando as metodologias utilizadas e a forma como identificamos componentes da criatividade que foram despertados e desenvolvidos. Sendo assim, não nos ateremos a descrever os detalhes de realização de cada oficina e sim o contexto em que elas ocorreram, já que o nosso objeto de estudo consiste no projeto de extensão Teoria e Investigação em Matemática Elementar, o TIME.

No presente trabalho descrevemos um referencial teórico que consistiu nas abordagens de Resolução de Problemas com base em Polya (2006) e Azevedo (2002), e na Investigação 
Matemática de Ponte, Brocardo e Oliveira (2006), em um contexto de oficinas de Matemática. Em seguida, discorremos a respeito da metodologia da pesquisa e, logo após, realizamos a descrição das 3 oficinas e suas análises. Por fim, apresentamos as considerações finais e as referências.

\section{Referencial Teórico}

Basicamente, no trabalho do TIME utilizam-se duas abordagens conhecidas na Educação Matemática como Investigação Matemática e Resolução de Problemas, dentre outros aspectos. Para Ponte, Brocardo e Oliveira (2006, p. 13), "Investigar é procurar conhecer o que não se sabe". Braumann (2002) exemplifica essa faceta investigativa com o aprender a andar de bicicleta. Você não consegue andar simplesmente olhando os outros e recebendo informações. Para verdadeiramente aprender o indivíduo deve subir na bicicleta, cometer erros e aprender com eles.

Um dos grandes matemáticos do século XX, Henri Poincaré, tentava demonstrar a impossibilidade de existência de funções com certo tipo de característica quando concluiu exatamente o oposto - que essas funções existem e chamou-as de "funções fuchsianas" (Ponte, Brocardo e Oliveira, 2006). Ou seja, o pesquisador deixou-nos a lição de que a construção pelo conhecimento matemático surge em momentos e em acontecimentos inesperados de "vai e vem" contrastando com a forma rígida e de certezas absolutas que a Matemática é apresentada, principalmente, aos alunos em sala de aula. Mas, não precisamos ir muito além. Até os problemas mais simples, porém curiosos e desafiadores, podem ser explicados por uma linguagem matemática adequada de forma que padrões e comportamentos possam ser alvo de estudos, até mesmo, de estudantes da Educação Básica.

Mas, por que as investigações matemáticas são importantes para os estudantes da Educação Básica? Ponte et al. (1998) atribui a sua importância a diversos motivos: estimulam o envolvimento do aluno; fornecem possibilidades de investigações adequadas a cada nível de capacidade; proporcionam um modo holístico de pensar; estimulam a necessidade de justificar suas afirmações, dentre outros motivos. Além disso, as novas perspectivas da filosofia da Matemática enfatizam esse tipo de atividade e pesquisadores como Polya (1975) e Caraça (1958), também ressaltam a importância de um trabalho baseado na reflexão e no apuramento de resultados que permitam o surgimento de hesitações e dúvidas.

Portanto, a Investigação Matemática está subsidiada por quatro momentos: exploração e formulação de questões; conjecturas; testes e reformulação; justificação e avaliação (PONTE; BROCARDO; OLIVEIRA, 2006). Isso não significa que a ordem dos momentos não possa ser invertida e nem que, dependendo da situação, um dos momentos não aconteça, mas o grande desafio é constituir diferentes tipos de tarefa capazes de promover o desenvolvimento matemático compondo um conhecimento propício para alavancar o interesse e as descobertas que podem ser realizadas na Matemática. 
A abordagem baseada na Resolução de Problemas também tem prioridade durante nossos encontros.

Problema, para nós, é tudo aquilo que não sabemos fazer, mas que estamos interessados em fazer. Assim, problemas com enunciados, exercícios simples ou complexos ou ainda demonstrações, de qualquer natureza, que não sabemos fazer, constituem-se em problemas (AZEVEDO, 2002, p. 97).

O termo Resolução de Problemas é sugerido por Polya (1997) como encontrar os meios desconhecidos para um fim nitidamente imaginado. Se o fim por si só não sugere de imediato dos meios, temos que procurá-los refletindo conscientemente sobre como alcançar o fim, temos de resolver o problema.

Entendendo George Polya como um dos precursores na Resolução de Problemas, consideramos o uso de uma metodologia heurística para resolver problemas como algo que proporciona a descoberta de novos fatos. Segundo Polya (2006), as heurísticas contemplam quatro momentos: compreensão do problema, estabelecimento de um plano, execução de um plano e retrospecto. Essas heurísticas sugeridas por G. Polya determinam um processo para que haja sucesso na sua resolução de problemas.

O grande lógico e matemático Bernard Bolzano, que dedicou grande parte da sua vida à lógica, sobre heurísticas nos diz:

Não me julgo, de maneira alguma, capaz de apresentar qualquer processo de investigação que não tenha sido já há muito tempo percebido por todos os homens de talentos e de forma alguma prometo que o leitor encontrará qualquer completa novidade neste assunto. Farei, no entanto, todo o possível para formular, em linguagem clara, as regras e os meios de investigação que são observados por todos os homens capazes, os quais, na maioria das vezes não tem sequer consciência de estarem seguindo. Embora não mantenha a ilusão de conseguir plenamente nem mesmo isso, ainda tenho a esperança do pouco aqui apresentado possa agradar alguém e encontrar mais tarde alguma aplicação (BOLZANO, 1781-1844, p. 293-295 apud POLYA, 2006, p. 40).

Desta forma, os autores deixam em aberto a possibilidade de se usar outros métodos, sendo as heurísticas um desses métodos possíveis que pode ser aplicado na Resolução de Problemas. Essa metodologia desperta o interesse e a curiosidade do indivíduo que a realiza, possibilitando uma grande alternativa para realizar a construção do conhecimento e o aprendizado da Matemática.

Além das abordagens apresentadas nesta seção, foi possível verificar que a aplicação e a utilização dessas metodologias para a aprendizagem e o desenvolvimento de uma nova visão da Matemática, proporciona um conhecimento diversificado estimulando a criatividade. De acordo com Vale (2012), a criatividade pode ser desenvolvida em três componentes: fluência, flexibilidade e originalidade. Para a pesquisadora, fluência é a capacidade de produzir um grande número de ideias; flexibilidade é o modo como mudamos de ideias quando se está a resolver um problema para encontrar várias soluções ou por optar por uma solução ótima; e originalidade é a capacidade de pensar produzindo ideias novas e únicas (VALE, 2012). 
Desta forma, observamos que os trabalhos realizados no contexto do TIME, desenvolvem e incentivam as componentes da criatividade, já que envolvem aspectos referentes à Investigação Matemática e à Resolução de Problemas em um contexto experiencial e de grupos colaborativos.

\section{Metodologia}

O presente trabalho consiste em uma pesquisa, cujo enfoque se faz através de um estudo de natureza qualitativa, pois "os pesquisadores qualitativos estudam coisas dentro de seus contextos naturais, tentando entender, ou interpretar, os fenômenos em termos dos significados que as pessoas Ihes atribuem" (DENZIN; LINCOLN, 2011, p. 3). Nesse sentido o enfoque da proposta metodológica segue o paradigma interpretativo na modalidade de observação participante na qual, segundo ROSA (2013, p. 63-64),

[...] o pesquisador está inserido em determinado grupo, no sentido de que faz parte dele, participando das ações desse grupo, enquanto o observa. $O$ pesquisador, como tal, não interfere no que o grupo faz ou deixa de fazer, isto é, o pesquisador não sugere ações ao grupo porque essas ações gerarão situações que deseja pesquisar. Ele contribui com o grupo como seu integrante.

Seguindo esses caminhos, observamos o modo como os participantes agem em trabalhos de aprendizagem matemática diferente das abordagens convencionais. Também observamos quais as possíveis dificuldades e suas ações para resolvê-las. Como dados coletados, consideramos os apontamentos levantados pelas falas, comportamentos e registros condicionados pelos alunos, e coletamos esses dados por meio de anotações das observações realizadas. A nossa pesquisa se deu em três oficinas realizada pelo programa de extensão TIME no ano de 2018 em que seus participantes, de modo geral, eram alunos da Educação Básica a nível de Ensino Fundamental e Médio.

Seguindo esses preceitos, consideramos a análise dos dados na modalidade de análise de observações, pois "a observação atenta dos detalhes põe o pesquisador dentro do cenário, para que possa compreender a complexidade dos ambientes psicossociais, ao mesmo tempo em que Ihe permite uma interlocução mais competente" (ZANELLI, 2002, p. 83). Nesse sentido, no intuito de analisar as contribuições das abordagens das metodologias de ensino Investigação Matemática e Resolução de Problemas, descrevemos três oficinas distintas que se realizaram aos sábados, com duração de quatro horas cada.

\section{Descrição das Oficinas e Discussões}

Para tentar entender a dinâmica, a organização e os elementos metodológico das oficinas do TIME, observamos a quantidade de alunos, ano escolar, colégio de origem público/privado, espaço físico, carga horária das oficinas, forma de exposição e interação.

A primeira oficina que iremos relatar teve o título: $\mathbf{O}$ espirógrafo: arte e matemática com a régua mágica. Esta foi realizada em um laboratório de informática, com 20 participantes, alunos da graduação em Matemática e professores de Matemática da Educação Básica. Tal oficina, teve 
como conteúdo estruturante "parametrização de curvas" por meio do uso do espirógrafo, ou régua mágica, e com o auxílio do software GeoGebra. A carga horária foi de 4 horas.

Inicialmente os alunos brincaram com a régua mágica (Figura 1), realizando desenhos aleatórios com canetas coloridas em uma folha de papel. Entendemos que esse momento inicial é importante, pois concordamos com Lorenzato (2006) que a ação do indivíduo sobre o objeto é básica para a aprendizagem. Ou seja, é necessário haver um contato inicial do participante com o material a ser explorado, antes do professor iniciar suas considerações, pois neste momento o indivíduo começa o reconhecimento do material.

Figura 1 - Régua Mágica.

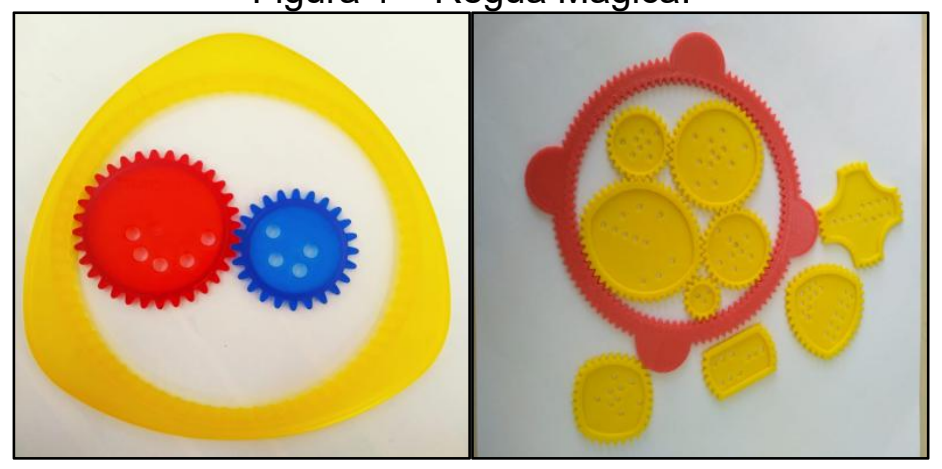

Fonte: Material da pesquisa (2019).

Na Figura 2, temos alguns desenhos feitos pelos participantes com a régua mágica.

Figura 2 - Espiras construídas com a régua mágica.

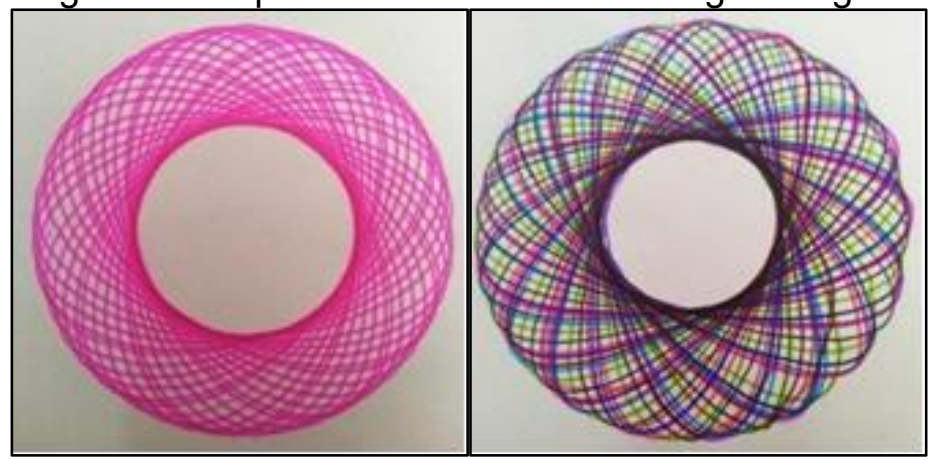

Fonte: Dados da pesquisa (2019).

Em seguida, foi sugerido que os participantes desenhassem no software GeoGebra algum dos desenhos que eles haviam reproduzido no papel com a régua mágica. Neste momento, como era previsto, os participantes apresentaram bastante dificuldade, pois não concebiam uma ideia para representar, exata ou aproximadamente, os desenhos realizados no papel com a régua mágica. Destacamos aqui que os participantes tinham conhecimento no GeoGebra, a dificuldade da representação das espiras construídas no papel para o software era de fato matemático. Assim, partindo das ideias dos alunos e de modo construtivo, o professor foi quebrando o problema em partes menores seguindo assim Polya (1975) de modo que gradativamente os alunos compreendessem as variações dos termos das parametrizações até chegar a uma formalização matemática. Esse foi o momento da institucionalização dos conceitos trabalhados durante o curso. 
Após discutir as dúvidas que eram apresentadas parametrizou-se uma das curvas construídas pelos participantes de tal modo que ficou assim:

$$
P=\{4 \cos (3 t)+2 \cos (-5 t), 4 \operatorname{sen}(3 t)+2 \operatorname{sen}(-5 t)\}
$$

e a curva obtida no GeoGebra ficou conforme a Figura 3.

Figura 3 - Espira construída no GeoGebra.

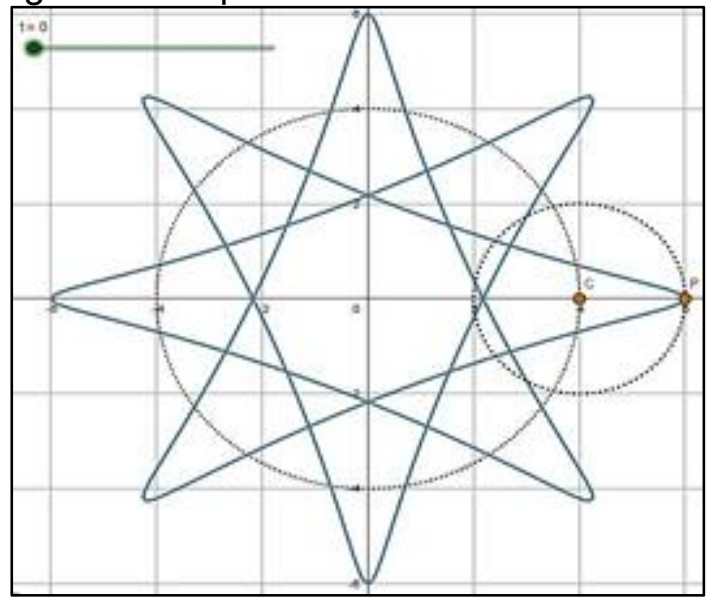

Fonte: Dados da pesquisa (2019).

Então, dispondo das ferramentas régua mágica, software GeoGebra e a parametrização de curvas, sugeriu-se que cada aluno desenhasse uma espira no GeoGebra e o seu vizinho deveria reproduzir essa mesma curva em seu computador utilizando-se dos conhecimentos de trigonometria e parametrização de curvas discutidos na oficina.

Por fim, o trabalho com o espirógrafo possibilitou uma reflexão acerca dos padrões, das generalizações, de criações de curvas, do conhecimento de lugares geométricos e das aplicações da trigonometria, despertando a curiosidade e o conhecimento matemático. Tal oficina proporcionou, além do resgate do uso do brinquedo régua mágica, o conhecimento de uma aplicação da trigonometria, a ideia de parametrização de curvas, uma relação entre o belo e a Matemática, o uso de um software de geometria e álgebra, uma outra forma de ensino e aprendizagem da trigonometria, dentre outras coisas. Entendemos, também, que o pensamento criativo foi incentivado e desenvolvido no momento em que o estudante mobiliza diferentes soluções que dependem da espira gerada e, além disso, comparam seus desenhos e suas soluções com os dos colegas já que dificilmente as espiras serão idênticas.

A segunda oficina observada foi a intitulada Razão e Proporção: uma construção da câmara escura. Esta oficina foi realizada com cerca de 20 estudantes da Educação Básica, do sexto ano do Ensino Fundamental ao terceiro ano do Ensino Médio e teve como conteúdo matemático "proporcionalidade direta e inversa" por meio da construção de uma câmara escura e sua aplicação; além disso, foi estudado um pouco sobre ótica e o como funciona uma câmara fotográfica. A oficina teve duração de 4 horas. Uma vez que o participante visualiza a imagem proporcionada pela câmara escura, e com as medições realizadas durante o experimento, efetua cálculos indicando a proporcionalidade direta e inversa, como podemos ver na Figura 4. 


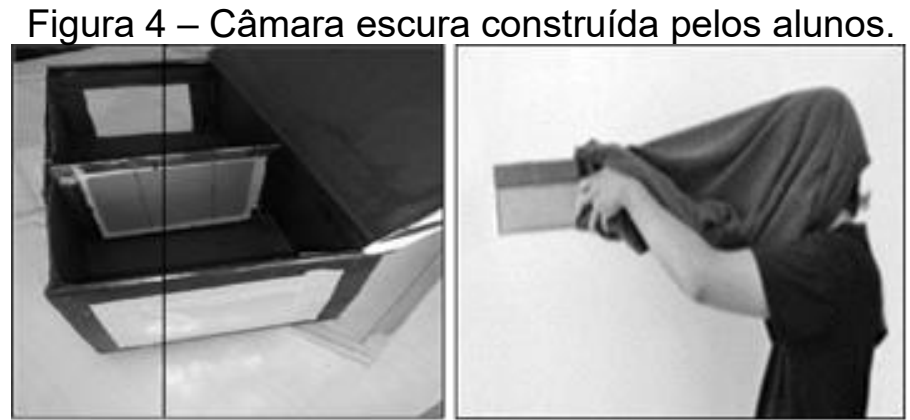

Fonte: Dados da pesquisa (2019).

Essa oficina seguiu quatro etapas que permitiram que o processo de investigação matemática realizado pelos participantes fosse minucioso. A primeira etapa foi uma apresentação a respeito da história da câmara fotográfica, na qual possibilitamos o conhecimento histórico da utilização da câmara escura, seu funcionamento e utilização até os dias de hoje, sendo realizada uma cronologia para a visualização da evolução deste equipamento.

A segunda etapa consistiu na construção da câmara escura. Nesse momento, os participantes demonstraram bastante entusiasmo sendo bem criteriosos quanto à forma de construção, pois os deixamos conscientes da necessidade de precisão e acertos no momento dos recortes e colagens, já que a câmara seria utilizada depois para extração de dados. No entanto, percebemos que alguns participantes apresentavam dificuldades de manuseio dos instrumentos como régua, tesoura, cola, instrumentos de medida em geral. Tal fato, se deve, talvez, por não estarem habituados a dinâmicas nessa estrutura. Porém, os monitores e professores presentes auxiliavam os alunos em todo o tempo no decorrer da construção da câmara escura.

A terceira etapa se baseou na aplicação e coleta de dados. Os dados foram coletados por meio de uma folha de registros entregue aos alunos que continha problemas de Matemática relacionados com uma aplicação prática da câmara escura construída por eles. Nesta etapa, os alunos se dividiram em quatro grupos de cinco ou quatro alunos cada de acordo com seus níveis de ensino. Nesta etapa, exploraram os primeiros três momentos descrito por Polya (2006) na metodologia heurística. No primeiro momento, discutiram e compreenderam os problemas propostos e no segundo momento estabeleceram um plano em que adequaram a câmara construída para extração das informações necessárias para iniciar a resolução dos problemas. Em seguida, como terceiro momento, executaram seus planos coletando os dados necessários de acordo com a folha de registros.

O conteúdo trabalhado por meio da folha de registros foi o de funções, em que foi realizada a construção de gráficos e tabelas, e também o encontro de razões e proporções. Durante a coleta dos dados para o preenchimento da folha e resolução dos problemas, os alunos desceram até o estacionamento do Departamento de Matemática onde a experiência estava sendo realizada, coletaram alguns dados com a trena e a câmara, e em grupos, preencheram a folha de registros. As dificuldades encontradas estavam basicamente em torno do manuseio da trena, bem como da 
necessidade de precisão no momento da coleta dos dados, e depois no registro desses dados. Os alunos que já conheciam o conteúdo de razão e proporção tiveram mais facilidade para preencher a folha, enquanto que os alunos que não conheciam o assunto demoraram mais tempo, pois precisaram de um acompanhamento maior por parte do professor e dos monitores. Porém, estes aprenderam a construir gráficos e interpretar, de forma superficial, os dados dos gráficos e das tabelas obtidas por eles mesmos.

A quarta etapa foi composta pelo fechamento do tema, em que realizamos uma conexão com todas as quatro etapas com a participação dos grupos, assim finalizamos a oficina. Esta oficina possibilitou uma relação da prática com a teoria, trabalhando as ideias de grandezas diretamente e inversamente proporcionais aliadas à percepção matemática dos participantes por meio da resolução de problemas. Além disso, o elemento flexibilidade da criatividade, definido por Vale (2012), foi incentivado na situação em que os alunos coordenaram os dados extraídos durante o experimento apresentando-os em forma de tabelas, gráficos e, por fim, concluindo em língua natural. Essa mobilização entre essas formas diferentes de representação evidencia o desenvolvimento da flexibilidade pelos alunos participantes.

E, a última oficina a ser relatada aqui é a oficina Astronomia e Trigonometria: a construção do Quadrante. Esta foi realizada com 30 estudantes e professores da Educação Básica com a finalidade de construir um instrumento astronômico chamado Quadrante. O Quadrante é um instrumento de medição que foi muito usado antes da invenção do telescópio, principalmente nas navegações. Ele é formado por um quarto de um círculo graduado com um fio de prumo, conforme a Figura 5. Sua principal função é possibilitar a medida da altura dos astros do sistema horizontal de coordenadas. Na figura 5 temos o Quadrante construído por um dos alunos.

Figura 5 - Quadrante construído por um dos alunos.

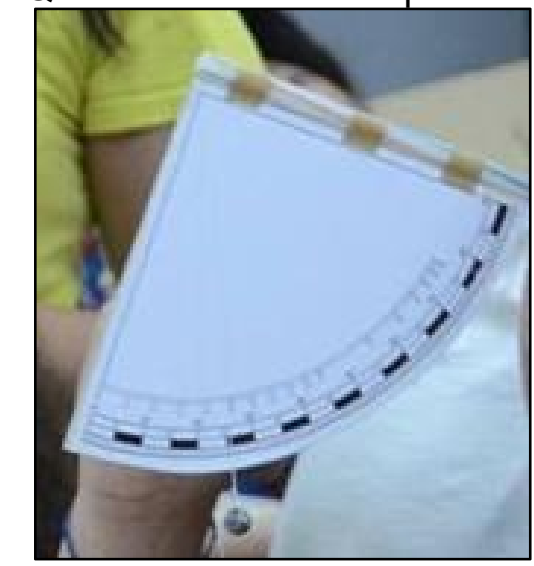

Fonte: Dados da pesquisa (2019).

Sua construção durante a oficina teve como objetivo promover um contexto de interdisciplinaridade ao relacionar o estudo da Matemática, Astronomia, Geografia, Física e História, proporcionando conhecimentos teóricos por meio da prática e experimentação do instrumento relacionado à Astronomia em um contexto da Matemática. 
No início da oficina, foram discutidos alguns aspectos teóricos referentes à geometria não euclidiana e à Astronomia, de modo que o bom uso do instrumento e suas conclusões fossem justificadas. Perguntas investigativas direcionaram a execução desse momento. A construção foi realizada individualmente com a ajuda dos professores ministrantes e dos graduandos em Matemática participantes do projeto.

Após a construção, fomos com os alunos até o estacionamento do Departamento de Matemática, onde solicitamos que estes utilizassem o Quadrante construído por eles para medir a altura do Sol naquele horário. O trabalho interdisciplinar com a Astronomia possibilitou aos alunos uma oportunidade para compreenderem conceitos astronômicos e propriedades matemáticas, pois durante a sua construção houve um resgate de conceitos de geometria não euclidiana para que pudessem compreender a aplicação do Quadrante.

\section{Considerações Finais}

Com este trabalho, objetivamos descrever e analisar algumas oficinas realizadas no contexto dos encontros do projeto de extensão Teoria e Investigação em Matemática Elementar da Universidade Estadual de Maringá. A intenção por divulgar este projeto é para incentivar outras instituições na realização de projetos semelhantes a este, contribuindo assim na interação entre alunos e professores da universidade com alunos e professores da Educação Básica, além de criar um espaço de experimentação e de metodologias que não são baseadas em repetições ou resoluções de exercícios para fixação.

Para este texto, descrevemos, de maneira breve, três oficinas sendo uma delas com o uso de um software geométrico e as outras com construções de materiais experimentais. Por meio de tais oficinas, trabalhamos conteúdos da Matemática, tais como: trigonometria; parametrização de curvas; razão e proporção; geometria não euclidiana; dentre outros assuntos da Matemática que são pré-requisitos para os principais.

Ao observar o desenvolvimento das oficinas, verificamos que os participantes desenvolvem uma nova e ampliada visão da aplicação matemática, pois a metodologia utilizada - Investigação Matemática e Resolução de Problemas - proporciona um conhecimento diversificado incentivando o aprendizado. Além disso, as componentes da criatividade - fluência, flexibilidade e originalidade - produzem um grande número de ideias que resultam no encontro de várias soluções ou de uma solução ótima podendo ser nova e única no contexto do participante em questão.

Como exposto nas seções anteriores, durante o desenvolvimento das oficinas e atividades do TIME, os participantes são incentivados a investigar uma determinada situação em que podem aparecer ou não perguntas como direcionamento destes momentos. Porém, o mais importante, é que as respostas não estão prontas e a exploração pode ir além do planejado, já que os materiais trabalhados possibilitam exploração de diversos assuntos da Matemática. O TIME utiliza dos quatro momentos da Investigação Matemática e da Resolução de Problemas, citados 
anteriormente, com o intuito de construir o conhecimento de seus participantes de modo lúdico e desafiante.

Tal ação, nos permite a reflexão da importância de elaborarmos ações para o ensino e a aprendizagem da Matemática que contribuem com o conhecimento matemático e desenvolva habilidades manuais, culturais e intelectuais.

Portanto, as propostas que são desenvolvidas durante os encontros do TIME, baseadas na Resolução de Problemas e na Investigação Matemática, por meio de oficinas, possibilita aos alunos o pensar de forma divergente e assim permite desenvolver seus próprios meios para resolver as tarefas propostas.

\section{Referências}

AZEVEDO, E. Q de. Ensino-aprendizagem das Equações Algébricas através da Resolução de Problemas. 2002. 186 f. Dissertação (Mestrado em Educação Matemática) - Pós-Graduação em Educação Matemática, Campus de Rio Claro, Instituto de Geociências e Ciências Exatas, Universidade Estadual Paulista, Rio Claro, SP, 2002.

BRASIL. Secretaria de Educação Fundamental. Parâmetros curriculares nacionais: Matemática. p. 148. Brasília: MEC/SEF, 1998.

BRAUMANN, C. Divagações sobre investigação matemática e o seu papel na aprendizagem da matemática. In.: PONTE, J. P.; COSTA, C.; ROSENDO, A. I.; MAIA, E.; FIGUEIREDO, N.; DIONÍSIO, A. F. (Eds.). Atividades de investigação na aprendizagem da matemática e na formação de professores. p. 5-24. Lisboa: SEM-SPCE, 2002.

CARAÇA, B. de J. Conceitos fundamentais da matemática. 3. ed. Lisboa: Tipografia Matemática, 1958. $319 \mathrm{p}$.

D’AMBRÓSIO, U. Matemática, ensino e educação: uma proposta global. Temas \& Debates, Rio Claro, ano IV, n. 3, p. 1-15, 1991.

DENZIN, N. K.; LINCOLN, Y. S. Introduction: the discipline and practice of qualitative research. In: DENZIN, N. K.; LINCOLN, Y. S. (Eds.). The SAGE handbook of qualitative research. 4. ed. p. 119. Thousand Oaks, CA: Sage, 2011.

GOMES, M. L. A escassez de professores de Matemática, Física e Química em teses e dissertações. In: MOSTRA ACADÊMICA UNIMEP - CONGRESSO DE PÓS-GRADUAÇÃO, 12., 2014, Taquaral. Anais... Taquaral: UNIMEP, 2014. Disponível em http://www.unimep.br/phpg/mostraacademica/anais/12mostra/8/652.pdf. Acesso em: 19 fev. 2019.

INEP. Instituto Nacional de Estudos e Pesquisas Educacionais Anísio Teixeira. Sistema de estatísticas Educacionais - Edutabrasil. 2011. Disponível em:

http://www.edudatabrasil.inep.gov.br. Acesso em: 19 fev. 2019.

LAMONATO, M.; PASSOS, C. L. B. Discutindo resolução de problemas e exploração-investigação matemática: reflexões para o ensino de matemática. Zetetiké, Campinas, SP, v. 19, n. 36, p. 5174, jul./dez. 2011.

LORENZATO, Sergio. Laboratório de ensino de matemática e materiais didáticos manipuláveis. In: LORENZATO, Sergio (Org.). O Laboratório de Ensino de Matemática na Formação de Professores. Campinas, SP: Autores Associados, 2006. 
PAIS, L. C. Didática da Matemática: uma análise da influência francesa. 2. ed. Belo Horizonte: Autêntica, 2002.

POLYA, G. A arte de resolver problemas. Rio de Janeiro: Interciência, 1975.

POLYA, G. Sobre a resolução de problemas de matemáticas high school. In: KRULIK, Stephen; REYS, Robert E. (Orgs.). Tradução de Hygino H. Domingues e Olga Corbo. A Resolução de Problemas na Matemática Escolar. São Paulo: Atual, 1997.

POLYA, G. A Arte de Resolver Problemas. Tradução: Heitor Lisboa de Araújo. 2. ed. Rio de Janeiro: Interciência, 2006. 203 p.

PONTE, J. P. da; BROCARDO, J.; OLIVEIRA, H. Investigações Matemática na Sala de Aula. 3. ed. rev., ampl., 2. reimp. Belo Horizonte: Autêntica, 2006. 160 p. Coleção Tendência em Educação Matemática.

PONTE, J. P. da; FERREIRA, C.; BRUNHEIRA, L.; OLIVEIRA, H.; VARANDAS, J. Investigando as Aulas de Investigações Matemáticas. Publicado originalmente em inglês com o título Investigating mathematical investigations. In: ABRANTES, P.; PORFIRIO, J.; BAÍA, M. (Orgs.). Les interactions dans la classe de mathématiques: Proceedings of the CIEAEM 49, Setúbal: Escola Superior de Educação de Setúbal, p. 3-14, 1998.

ROSA, P. R. da S. Uma introdução à pesquisa qualitativa em Ensino de Ciências. Campo Grande: Universidade Federal de Mato Grosso do Sul, 2013.

VALE, I. As tarefas de padrões na aula de matemática: um desafio para professores e alunos. Interacções, Portugal, v. 8, n. 20, p.181-207, 7 abr. 2012.

ZANELLI, J. C. Pesquisa qualitativa em estudos da gestão de pessoas. Estudos de Psicologia, Natal, v. 7, n. especial, p. 79-88, 2002. 